\title{
Psychological model of the development of moral and will qualities of cadets of the educational organizations of the FPS of Russia
}

\author{
Svetlana Yakovleva*, Ivan Kuptsov, Larisa Shatohina, and Nina Shilina \\ Academy of Law and Management of the FPS of Russia, Ryazan, Russia
}

\begin{abstract}
The modernization of the penal system of the Russian Federation places high demands on the training of highly qualified personnel in order to optimize the penal system and its quality functioning. The exceptional complexity of employees' activities dictates high requirements for the development of their moral and will qualities. We suggested that one of the ways to solve this problem will be to develop and implement a psychological model for the development of moral and will qualities of employees at the stage of their university training. The model is aimed at formation of professional self-awareness of employees through formation and development of spiritual and moral values, awareness of own personal and professionally important qualities, as well as motivation to improve them. The model presents step-by-step the movement from the set goal to the intended result, describes mechanisms of psychological support of the educational process: goal and tasks; principles; criteria of formation of moral and will qualities; content of activities on development of moral and will qualities; tools: forms, methods, means of development of moral and will qualities of cadets; result.
\end{abstract}

At present, Russian society is engaged in processes of renewal and optimization of activities in many spheres of social life, including the penal system. The Concept of the Development of the Penal system of the Russian Federation until 2020 has taken a course to modernize the penal system in connection with the reorientation of our country to the experience of Western Europe and the achievement of the most advanced countries in the field of penal enforcement, the need to take into account the interests and requirements of the international community to introduce international standards governing the treatment of prisoners. There is no doubt that these changes have also led to higher requirements for the training of highly qualified personnel.

One of the ways to solve the problem of the development of moral and will sphere of employees is to develop and implement a psychological model of the development of moral and will qualities of cadets of educational organizations of the FPS of Russia. The model reflects theoretical positions based on the realized complex of psychological conditions for the development of moral and will qualities of cadets at the stage of educational and professional training in the educational organization. The model takes into account the

\footnotetext{
*Corresponding author: ninashilina87@mail.ru
} 
specifics of the organization of professional training of the staff of the Federal Penal Service of the Russian Federation.

The first component of the model is goal-directed. The purpose of the process under study is determined by the social order, which is reflected in the Federal State Educational Standards of Higher Education. We formulate the goal as the development of moral and will qualities of cadets of educational organizations of the Federal Penal Service of the Russian Federation in the process of professional training.

Achieving the goal is possible through the following tasks:

- formation of positive motivation for professional training and development of moral and will qualities as its component;

- training in self-certification and self-development of moral and will qualities, skills of self-regulation and self-control necessary for professional activity;

- creation of conditions for acquisition and accumulation of experience of moral and will qualities in professional activity;

- study of the dynamics of the process of development of moral and will qualities on the basis of the results of initial and current diagnostics.

The second component of the model is methodological, represented by following principles:

- professional orientation;

- interpersonal interaction and dialogue of subjects of the educational process;

- taking into account the individual characteristics of the cadets;

- systematicity and consistency according to the psychological structure of the will act.

When choosing of the listed principles we were guided by key provisions of the concept of personal development (B.G. Ananyev [1], L.S. Vygotsky [2], etc.); spirituality (B.S. Bratus [3], L.N. Sobchik [4], V.D. Shadrikov [5], etc.); the ideas of V.A. Yakovlev [6] and his followers (S.B. Kaverin [7], M.I. Starov [8], etc.) about conditions and mechanisms of spiritual and moral formation of the personality.

The next component of the model is content-related. The main areas of activity of the pedagogical team for the development of moral and will qualities of cadets are theoretical, motivational and practical training.

Theoretical training is aimed at formation of value and cognitive components of moral and will qualities (arming cadets with general professional knowledge; mastering of technology of self-development of moral and will qualities; knowledge in the field of specifics of functioning of the FPS of Russia).

Motivational training involves the development of a motivational component (formation of interest in professional activity and motivational readiness to show moral and will qualities; familiarization with the experience of the staff of the Federal Correction Service of the Russian Federation).

Practical training is aimed at the formation of behavioral and reflexive components (use of theoretical knowledge in educational and quasi-professional activities; development of situations requiring the manifestation of moral and will qualities; accumulation of experience of interpersonal interaction in extra-school activities; development of these qualities in the process of industrial practice).

Psychological training accumulates these areas of activity, in the process of which skills of self-assessment, self-analysis, and self-regulation are worked out.

The next component of the model is procedural and technological. It includes:

- forms of interaction with cadets (individual, frontal, group);

- methods of interaction, including explanation, problem situations, simulation methods, analysis of specific situations and professional tasks, as well as competitive and evaluation methods; 
- tools: both general, applied for any element of the educational process, and special, used for psychological training. At the same time, the general funds provided for the organization of special, extremely close to professional activity employees of the FPS.

The study of psychological conditions of the formation of personal and professional qualities of cadets during studies in higher educational institutions is devoted to the work of S.V. Chebrovskaya [9], etc. Factors influencing the formation of the will qualities of the person are reflected in the works of L.I. Bozhovich [10], I.I Kuptsov [11], V.I. Selivanov [12], A.V. Simonenko [13], etc. The authors note that youth age, on the one hand, is characterized by a certain experience of moral behavior, and on the other - is the most favorable for the development of moral and will qualities, thanks to the actualizing need for self-improvement and self-development.

Carried out analysis of scientific literature, own experience of professional activity allowed to determine psychological conditions necessary for formation of investigated qualities.

The first condition is a purposeful impact on the development of the will and moral qualities of cadets. Realization of this condition implies organization and carrying out of events aimed at development of will and moral qualities of cadets, for which different forms of work are used: talks, cinema-trainings, social-psychological trainings, etc.

The second condition is the organization of interaction of cadets in micro groups, specially aimed at the development of moral and will qualities of the person.

The micro-environment of cadets differ significantly from the student environment, as the cadets live in barracks, their regime of the day differs significantly from the student, it is strictly regulated, special attention is paid to basic, physical, fire training, cadets spend a lot of time together both in educational and out-of-school time.

The third condition is aimed at acquisition by cadets of moral and will experience as a driving force of personality development, as well as consolidation of acquired attitudes for realization of professional activity. A significant aspect that must be taken into account is the use of collective activities involving the realization of this condition in extra-school time (preparation for tournaments, festivals, etc.).

The fourth condition is characterized by the application of systematic analysis and moral assessment by both teachers and cadets of the motives for the actions and behavior of each member of the training group.

The last element of the model is the performance component.

The result is a high level of the formation of moral and will qualities of cadets. Such a level is characterized by the presence of formed moral ideals and principles of cadets, which serve as regulators of his behavior and the direction of moral-will efforts. Characteristic for cadets with a high level of formation of moral-will qualities moral stability of the person as the ability to preserve and realize in various conditions personal positions, to have a certain immunity to negative effects is accompanied by stable manifestation of moral-will qualities both in everyday activity, in educational and educational-production with its transition to professional. The moral and will activity of the cadet at the same time is based on the system of holistic sense formations available to him, knowledge of moral and ethical norms defining the professional activity of the employee of the Federal Penal Service of the Russian Federation.

In addition, the effective component of the model includes criteria for their formation:

- the moral-value criterion characterizes the vector of the will effort in a particular situation, making the meaning of its manifestation, which, according to I.M. Sechenov, allows a person to perform a moral feat, which in case of overcome difficulties gets a positive emotional tone [14]. 
- motivational criterion. Motivation aimed at achieving the intended goal and the establishment of a position to combat the difficulties that arise along the way makes it possible to form a will effort and bring the work started to an end;

- cognitive criterion is a set of knowledge and perceptions of cadets about moral values and will qualities, which determine the possibilities of self-improvement of the individual;

- the behavioral criterion implies that the characteristics of a person's moral education depend on the dialectic of the moral regulation of his or her behavior, as well as on the individual attitude towards the surrounding and, in general, the system of values and moral beliefs;

- reflexive criterion implies self-evaluation of own moral-will qualities and acts, their correlation with existing ethical norms and values. The ability to reflect and self-regulate helps cadets to develop the ability to analyze and critically assess their capabilities, to solve professional tasks qualitatively in different conditions, including extreme ones.

The development of each criterion is determined by means of specific indicators:

- a value criterion: the adoption of sustainable moral ideals, rules and norms in situations of moral choice that facilitate the transition of knowledge into persuasion in vocational training;

- motivational criterion: development of motivation to acquire moral and will qualities, level of professional interest;

- cognitive criterion: moral knowledge, representations, concepts, evaluation judgements, knowledge of professional ethics norms;

- behavioral criterion: experience of moral and will behavior (ability to behave with restraint, to bring the started business to the end, to organize the activities, etc.);

- reflexive criterion: assessment of self and own actions from the point of view of moral and moral norms.

The psychological model with all its components in their relationship and interdependence allows to present the development of moral and will qualities of cadets of educational organizations of FSIN of Russia taking into account reflexive, empirical and analytical-generalizing processes, psychological factors.

\section{References}

1. B.G. Ananiev, Man as a subject of knowledge (Piter, St. Petersburg, 2001)

2. L.S. Vugotsky, Pedagogical Psychology, (Pedagogy, Moscow, 1996)

3. B.S. Bratus, Personality Anomalies (Mysl', Moscow, 1988)

4. L.N. Sobchik, Introduction to the psychology of individuality (Institute of Applied Psychology, Moscow 2000)

5. V.D. Shadrikov, Problems of systemogenesis of professional activity (Nauka, Moscow, 1982)

6. V.A. Yakovlev, The psychological characteristic of the semantic sphere of personality of prisoners sentenced to imprisonment (Ryazan 1999)

7. S.B. Kaverin, Motivation of Labor (Institute of Psychology RAS, Moscow, 1998)

8. M.I. Starov, Formation of a system of relations in the course of teacher training (Moscow, 1996)

9. S. Chebrovskaya, Psychological Conditions for the Formation of Independence among Students (Komsomolsk-on-Amur, 2003)

10. L.I. Bozhovich, Family and school, 1, 32-35 (1981)

11. I.I. Kuptsov, Applied Law Psychology, 2, 146-151 (2010)

12. V.I. Selivanov, Selected psychological works (will, its development and upbringing) (Ryazan Pedagogical Institute, Ryazan 1992) 
13. A.V. Simonenko, Herald of University of the Ministry of Internal Affairs of the Russian Federation, 4, 119-124 (2015)

14. I.M. Sechenov, Selected works (State Pedagogical Publishing House of the Ministry of Education of the RSFSR, Moscow, 1953) 